\title{
Avaliação das premissas do Programa de Reestruturação e Ajuste Fiscal e seus impactos para a situação físcal dos Estados brasileiros
}

\author{
Fabrício Marques Santos ${ }^{*}$ \\ Marco Aurélio Alves de Mendonça** \\ Gustavo Tavares Lameiro da Costa** \\ Renata G. Rimes de Almeida ${ }^{* * *}$ \\ Gabriel Silva Goes Rodrigues**** \\ George André Palermo Santoro ${ }^{* * * * *}$
}

RESUMO - O estudo possui dois objetivos, a saber: discutir as premissas inerentes aos programas de reestruturação e ajuste fiscal (PAF) firmados entre a União e os Estados brasileiros; e propor uma equação formal da relação dívida financeira/receita que garanta para esta a convergência para a meta prevista nos contratos. Para dar conta dos objetivos realizouse revisão da legislação pertinente, a partir da qual foi formalizada matematicamente a equação de convergência. Os resultados indicam que os Estados que possuírem relação dívida financeira/receita líquida real inferior ou igual a 2,50, em 2009, tendem a cumprir a meta de redução de endividamento prevista pelo PAF, em 20 anos. Aponta-se também o desvio das hipóteses do PAF causado pela indexação da dívida ao IGP.

Palavras-chave: Endividamento estadual. Ajuste fiscal. LRF. Reestruturação da dívida.

\section{INTRODUÇÃO}

A Lei Complementar $\mathrm{n}^{\circ}$ 101, de 4 de maio de 2000, intitulada Lei de Responsabilidade Fiscal (LRF), representou o mais importante marco institucional na tarefa de reforçar os princípios de austeridade fiscal subentendidos no Programa de Reestruturação e Ajuste Fiscal (PAF) dos Estados. Ela complementou o trabalho de consolidação da dívida pública dos Estados efetuado na década de 1990 por meio da Lei 8.727 e, principalmente, da Lei 9.496 de 1997 que tornou a União credora dos Estados. Como parte desta negociação, os Estados, além de terem assumido encargos contratuais de serviço de dívida com a União,

\footnotetext{
- Os autores fazem parte da equipe da Subsecretaria de Política Fiscal (SUPOF), da Secretaria de Estado de Fazenda do Estado do Rio de Janeiro e agradecem os valiosos comentários do secretário Joaquim Levy.

* Mestre em Economia pela FEA/USP.

** Doutor em Engenharia de Sistemas e Computação pela UFRJ.

*** Mestre em Estatística pela ENCE.

**** Especialista em Negociações pela UnB.

***** Mestre em Economia pela UFSC.

****** Especialista em Administração Pública, pela FGV-RJ, e em Economia Empresarial e em Direito do Trabalho, ambos pela UCAM-RJ.
} 
estão submetidos a Programas de Ajuste Fiscal—PAF, que impõem limites aos seus gastos e endividamento.

Nos últimos anos, ainda que os Estados tenham cumprido os contratos e empreendido esforços para limitar seus gastos primários, a trajetória da dívida tem se apresentado menos favorável do que o planejado. Além disso, após quase uma década de ajuste fiscal os Estados apresentam forte demanda por investimentos, que não pode ser eficientemente atendida apenas com receitas correntes, aí incluídas eventuais transferências da União. Em vista disto, tem havido uma retomada da discussão sobre a magnitude dos encargos da dívida com a União, o reajuste do saldo devedor e sobre os limites ao endividamento dos Estados.

Esse trabalho procura iluminar essa discussão proporcionando um marco teórico para a discussão dos limites de endividamento e analisando algumas das causas para o eventual desvio na trajetória projetada para a relação dívida-receita, e suas conseqüências para a programação fiscal de longo prazo, inclusive no que toca ao uso de receitas de capital para financiar a infra-estrutura.

\section{QUADRO INSTITUCIONAL DA RELAÇÃO ESTADOS-UNIÃO}

A reestruturação da dívida dos entes estaduais e municipais iniciou-se em 1989, com a Lei 7.977. Em 1993, a Lei 8.727 permitiu a renegociação da dívida de Estados e municípios com a União e instituições federais, num momento em que a inflação e a estagnação econômica geravam perspectivas extremamente negativas para todos os entes da Federação.

Em 1996, a dívida de Estados e municípios chegou a atingir 16,6\% do PIB nacional, constituindo grave ameaça à estabilidade macroeconômica. Por isso, tornou-se premente uma saída negociada no âmbito da federação e, em resposta ao pleito da esfera estadual, a União propôs o PAF, formalizado pela Lei 9.496/97.

O PAF foi estabelecido sobre três pilares, a saber: ajuste fiscal (para viabilizar o pagamento das prestações associadas ao refinanciamento), venda de ativos estaduais (particularmente a desestatização de concessionárias estaduais de distribuição de energia) e privatização/liquidação dos bancos estaduais.

O ajuste fiscal foi engendrado a partir da limitação de novo endividamento e a obrigação contratual de serviço da dívida com a União. As identidades da contabilidade pública demonstram que na ausência de receitas não primárias, o equilíbrio orçamentário se alcança com a geração de um superávit primário equivalente ao serviço da dívida. O controle 
das duas variáveis (endividamento novo e serviço da dívida existente) permitiu à União garantir nos últimos anos um resultado primário crescente por parte dos entes subnacionais (esse resultado correspondeu a $21,97 \%$ do resultado primário consolidado de 2008, de acordo com o Banco Central).

Um dos instrumentos da União para garantir o pagamento da dívida pelos Estados é o dispositivo constitucional que permite à União reter as transferências constitucionais a Estados inadimplentes, e acessar as contas onde são recolhidos os tributos próprios desses entes. O PAF, por outro lado, é um programa com diversas metas, que é negociado individualmente entre cada Estado e a União periodicamente. A certificação da adimplência ao PAF é essencial para qualquer estado contratar operações de crédito.

Uma das principais metas do PAF é a trajetória atualizada do quociente Dívida Financeira/Receita Líquida Real (RLR) ${ }^{1}$. O acompanhamento dessa trajetória é essencial para que se alcance um dos objetivos fundamentais do contrato, i.e., a redução da dívida financeira do estado a um valor não superior ao da sua RLR, ao cabo de determinado prazo. Para que esse objetivo seja alcançado, é necessário o estabelecimento de uma tendência de redução anual da relação DF/RLR relativa à existente no momento da celebração do contrato, alcançando-se percentuais cada vez menores, até atingir-se valor inferior a "um".

Uma vez que tal objetivo consta na lei, a interpretação da regra na Lei 9.496 de que um Estado para se endividar tem que demonstrar o cumprimento das "metas da dívida" previstas no PAF passou a ser que o Tesouro deve estar confortável com a trajetória que a dívida assumirá após a contratação da operação de crédito pretendida.

A questão que se coloca, portanto, é como o Tesouro pode definir uma trajetória que seja consistente com os aspectos fundamentais da Lei 9.496. Durante muitos anos essa questão não foi muito relevante, porque os contratos originais previam um espaço inicial, ou seja, um montante acima da dívida já existente que poderia ser utilizado pelos Estados se eles estivessem cumprindo as outras metas do PAF. Mais recentemente, no entanto, este espaço se esgotou, enquanto as demandas por investimentos continuam se renovando. $\mathrm{O}$ desenvolvimento de um marco teórico que permita Estados e União dialogarem e que garanta de maneira transparente a responsabilidade fiscal e a realização dos objetivos da Lei 9.496, tornou-se assim de grande interesse.

\footnotetext{
1 Trata-se da receita realizada nos doze meses anteriores ao mês imediatamente anterior àquele em que se estiver apurando, excluídas as receitas provenientes de operações de crédito, de alienação de bens, de transferências voluntárias ou de doações recebidas com o fim específico de atender despesas de capital e, no caso dos Estados, as transferências aos municípios, por participações constitucionais e legais.
} 


\section{ANÁLISE DA TRAJETÓRIA DA RELAÇÃO DF INTRALIMITE² /RLR}

A trajetória da relação Dívida Intralimite/RLR dos Estados pode ser derivada analiticamente a partir das características e hipóteses previstas no contrato formalizado pela Lei $9.496 / 97^{3}$. Essas hipóteses e parâmetros têm a ver basicamente com a variável de controle (relação dívida-receita), e as taxas "reais" de crescimento da dívida (taxa de juros) e da receita (suposta 3\% a.a.), assim como a hipótese de que o crescimento nominal de ambas as variáveis se daria proporcionalmente a um mesmo indexador (o IGP-DI). Isto porque a dívida consolidada paga juros de $6 \%$ sobre um estoque que é mensalmente reajustado pelo IGP.

A hipótese é que este indexador também se reflete no crescimento nominal da base tributária dos Estados (ICMS, mais transferências da União). O crescimento real da receita deve refletir a taxa de crescimento do PIB potencial, mas o PAF tem outro aspecto fundamental: a limitação do serviço da dívida em 13\% da RLR do estado. Se o serviço determinado pelos juros de 6\% ultrapassa esse valor, o excesso é capitalizado, formando o chamado "resíduo" da dívida.

É interessante notar, de um lado, o extraordinário esforço fiscal implícito neste programa, visto que por hipótese e construção se prevê um crescimento real da dívida duas vezes mais rápido que o da economia. E do outro lado, o aspecto anticíclico da sua arquitetura. A razão para tal esforço seria a situação em 1997, quando o Brasil apresentava grandes desequilíbrios macroeconômicos, com fragilidade externa, que se traduzia por uma taxa de juros real para a União freqüentemente de dois dígitos anuais.

O ponto notável do arcabouço por traz da Lei 9.496 é que ela reflete o típico modelo de solvência da dívida, com a complicação do limite dos 13\%. Curiosamente, ele nunca foi discutido extensamente, tanto na academia quanto nas negociações entre Estados e União. Esse trabalho formaliza o arcabouço e discute suas conseqüências para o limite da dívida.

\subsection{DERIVAÇÃO DA EQUAÇÃO DA RELAÇÃO DF/RLR}

$$
\begin{aligned}
& \text { Seja: } \\
& V=\frac{x}{r}
\end{aligned}
$$

Onde: $x$ é a divida e $r$ é a receita, ou seja, $V$ é a relação divida/receita.

\footnotetext{
${ }^{2}$ Dívidas cujas prestações são pagas com uma proporção fixa da RLR, que geralmente é de 13\%.

${ }^{3}$ Supondo, por simplificação, que toda Dívida Intralimite seja formada por dívida renegociada sob a Lei 9.496.
} 
A variação de $V$ é dada por:

$$
\frac{d V}{V}=\frac{D x}{x}-\frac{d r}{r}
$$

Se

$$
D x=i x-s r
$$

Onde: $D x=x(t)-x(t-1) ; i$ é a taxa de juros da dívida; e $s$ é o limite máximo da receita usada para pagamento do serviço da dívida, ambos considerados constantes.

Alternativamente,

$$
\frac{D x}{x}=i-s \frac{r}{x}=i-\frac{s}{V}
$$

Logo, se

$$
\frac{D x}{x}=\frac{d x}{x}
$$

Tem-se:

$$
\frac{D V}{V}=i-\frac{d}{r}-\frac{s}{V}
$$

Se

$$
\frac{D r}{r}=g
$$

Então

$$
\frac{D V}{V}=i-g-\frac{s}{V}
$$

Daí

$$
D V=(i-g) V-s
$$

$\mathrm{Ou}$

$$
D V-(i-g) V=-s
$$

Resolvendo a equação diferencial de primeira ordem com termo e coeficiente constantes (caso não homogêneo), tem-se:

$$
V(t)=\left[V(0)-\frac{s}{(i-g)}\right] e^{(i-g) t}+\frac{s}{i-g}
$$


Com objetivo de verificar a relação inicial $[\mathrm{V}(0)]$ máxima para que a relação $\mathrm{DF}$ Intralimite/RLR convirja para "1" em 2029, conforme a meta prevista no PAF da maioria dos Estados partiu-se da equação (1).

$$
\begin{aligned}
& \text { Se } V(20)=1 \text {, então: } \\
& {\left[V(0)-\frac{s}{(i-g)}\right] e^{(i-g) 20}+\frac{s}{i-g}=1} \\
& {\left[V(0)-\frac{s}{(i-g)}\right] e^{(i-g) 20}=1-\frac{s}{i-g}} \\
& V(0)=\left[\frac{i-g-s}{i-g}\right] e^{-(i-g) 20}+\frac{s}{(i-g)}
\end{aligned}
$$

Efetuando os cálculos para parâmetros i $=6 \%$ e s=13\%; e hipótese básica de g=3\%, tem-se:

$$
\begin{aligned}
& V(0)=-\left[\frac{0,1}{0,03}\right] e^{-0,6}+\frac{0,13}{0,03} \\
& V(0)=2,5
\end{aligned}
$$

O resultado indica que Estados com relação DF Intralimite/RLR menor ou igual a 2,5 em 2009 e que não apresentarem saldo de dívida extralimite em 2029 atenderão à condição de DF/RLR menor ou igual a "um” em 2029, último ano da maioria dos contratos celebrados sob a Lei $n^{\circ}$ 9.496/97.

Em contrapartida, os Estados que apresentarem relação DF Intralimite/RLR superior a 2,5 em 2009, supondo as hipóteses básicas do programa, não terão a relação convergente para " 1 ” após os trinta anos da assinatura do contrato original.

\subsection{SIMULAÇÕES DE CONVERGÊNCIA DA RELAÇÃO DF INTRALIMITE/RLR}

Para avaliar a sensibilidade da trajetória aos parâmetros, a tabela 1 mostra qual seria o valor da relação DF Intralimite/RLR em função de diferentes condições iniciais, taxas de juros e taxa de crescimento da receita, supondo o comprometimento de $13 \%$ da receita líquida real (percentual previsto em contrato). 
TABELA 1 - RELAÇÃO DÍVIDA FINANCEIRA/RLR AO FINAL DE 20 ANOS, SUPONDO O COMPROMETIMENTO DE 13\% DA RLR

\begin{tabular}{|c|c|c|c|c|c|c|c|c|c|c|c|c|c|}
\hline \multicolumn{5}{|c|}{ Taxa de juros real } & \multicolumn{3}{|c|}{$4 \%$} & \multicolumn{3}{|c|}{$5 \%$} & \multicolumn{3}{|c|}{$6 \%$} \\
\hline \multirow{4}{*}{ 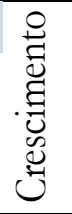 } & \multirow{4}{*}{ 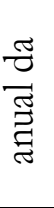 } & \multirow{4}{*}{ 苞 } & \multirow{4}{*}{ 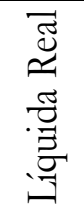 } & & $\mathrm{V}_{\mathrm{O}}=2,2$ & $\mathrm{~V}_{\mathrm{O}}=2,5$ & $\mathrm{~V}_{\mathrm{O}}=2,8$ & $\mathrm{~V}_{\mathrm{O}}=2,2$ & $\mathrm{~V}_{\mathrm{O}}=2,5$ & $\mathrm{~V}_{\mathrm{O}}=2,8$ & $V_{0}=2,2$ & $V_{O}=2,5$ & $\mathrm{~V}_{\mathrm{O}}=2,8$ \\
\hline & & & & $2 \%$ & 0,00 & 0,34 & 0,75 & 0,25 & 0,75 & 1,24 & 0,66 & 1,27 & 1,87 \\
\hline & & & & $3 \%$ & 0,00 & 0,18 & 0,54 & 0,09 & 0,53 & 0,98 & 0,45 & 0,99 & 1,54 \\
\hline & & & & $4 \%$ & 0,00 & 0,03 & 0,36 & 0,00 & 0,34 & 0,75 & 0,25 & 0,75 & 1,24 \\
\hline
\end{tabular}

FONTE: Elaboração Própria.

É evidente o tremendo impacto de qualquer redução na taxa de juros—a relação DF intralimite/RLR após vinte anos com juros de 5\% $(0,53)$ é a metade daquela da hipótese central com juros de 6\% (0,99). A redução do limite de pagamento para $12 \%$ da RLR, sem mudança na taxa de juros, por outro lado, leva a uma deterioração da trajetória bastante significativa (Tabela 2$)^{4}$

TABELA 2 - RELAÇÃO DÍVIDA FINANCEIRA/RLR AO FINAL DE 20 ANOS, SUPONDO O COMPROMETIMENTO DE 12\% DA RLR

\begin{tabular}{|c|c|c|c|c|c|c|c|c|c|c|c|c|c|}
\hline \multicolumn{5}{|c|}{ Taxa de juros real } & \multicolumn{3}{|c|}{$4 \%$} & \multicolumn{3}{|c|}{$5 \%$} & \multicolumn{3}{|c|}{$6 \%$} \\
\hline \multirow{4}{*}{ 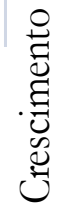 } & \multirow{4}{*}{$\frac{\underset{\Xi}{\Xi}}{\underset{\Xi}{\Xi}}$} & \multirow{4}{*}{ 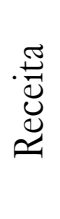 } & \multirow{4}{*}{ 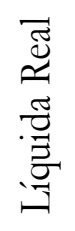 } & & $V_{0}=2,2$ & $\mathrm{~V}_{\mathrm{O}}=2,5$ & $V_{0}=2,8$ & $V_{0}=2,2$ & $V_{0}=2,5$ & $V_{0}=2,8$ & $\mathrm{~V}_{\mathrm{O}}=2,2$ & $\mathrm{~V}_{\mathrm{O}}=2,5$ & $V_{0}=2,8$ \\
\hline & & & & $2 \%$ & 0,17 & 0,58 & 0,98 & 0,51 & 1,01 & 1,50 & 0,95 & 1,56 & 2,16 \\
\hline & & & & $3 \%$ & 0,03 & 0,40 & 0,76 & 0,33 & 0,78 & 1,23 & 0,72 & 1,27 & 1,81 \\
\hline & & & & $4 \%$ & 0,00 & 0,24 & 0,57 & 0,17 & 0,58 & 0,98 & 0,51 & 1,01 & 1,50 \\
\hline
\end{tabular}

FONTE: Elaboração Própria.

\subsection{OUTRAS CONSIDERAÇÕES}

Uma das principais premissas do PAF capturada nesse modelo é que a dinâmica da dívida pode ser tratada a preços constantes. Isto é devido à premissa de que receita e serviço da dívida são deflacionadas pela mesma taxa. No entanto, a experiência dos últimos 12 anos tem sido outra. Isto se deve essencialmente à escolha do indexador que corrige o estoque da dívida, o qual não guarda relação coerente com a base tributária dos Estados. Em vista do limite de $13 \%$ da receita, isto tem levado à geração de resíduos e sua capitalização, desacelerando a redução do estoque da dívida.

\footnotetext{
${ }^{4} \mathrm{O}$ modelo acelera um pouco o ritmo de pagamento previsto no PAF, porque ele supõe que o serviço da dívida será sempre igual a $13 \%$ ou $12 \%$ da RLR, quando de acordo com as regras do contrato pode ocorrer que ao estoque da dívida diminuir o serviço fique menor que o limite assumido. No modelo não há uma regra de transição para lidar com este caso, o que pode, no entanto, se facilmente incluído em modelos numéricos criados a partir dessas equações.
} 
O entendimento convencional para a escolha do IGP-DI como indexador é de que no final da década de 1990, o IBGE, fundação do governo federal responsável pelas estatísticas oficiais, enfrentava longos períodos de paralisação das atividades por conta de seguidas greves, o que dificultaria o cumprimento do contrato. Assim, julgou-se prudente utilizar o índice produzido pela Fundação Getúlio Vargas (FGV) do Rio de Janeiro, instituição privada, menos sujeita aos problemas então passados pelo IBGE.

No entanto, já naquele momento, era consenso que o IGP não era um bom indexador por conta de sua volatilidade decorrente de variações na taxa de câmbio e preços das commodities. Isto foi confirmado várias vezes nos últimos 12 anos. Em 2007 e 2008, mais uma vez o IGP ultrapassou em muito o IPCA e outros índices mais aderentes à base tributária do ICMS, tendo crescido 7\% em 2007 e 9\% em 2009. A conseqüência foi que, a despeito dos Estados terem cumprido suas metas de primário e de serviço da dívida, a trajetória da relação da DF/RLR acabou ficando acima dos valores acordados ${ }^{5}$. Tal comportamento não é surpreendente, e equivaleria a se ter aumentado a taxa de juros real da dívida em um ou dois pontos percentuais. O efeito deste desvio no comportamento do índice e negação de uma hipótese básica do modelo pode ser explosivo no longo prazo (o IGP apresentou um excesso superior a 32 pontos percentuais em relação ao IPCA nos últimos dez anos).

Assinale-se que os problemas do IGP são agravados por duas características do contrato, uma das quais, na verdade de caráter idiossincrático. A primeira é o reajuste do estoque da dívida ser mensal, potencializando o efeito da divergência IGP-IPCA (base tributária). A outra é que o Tesouro não corrige para baixo o estoque da dívida quando o IGP é negativo. Ou seja, a dívida só cresce. Esse último aspecto, obviamente, não tem base legal, e já foi corrigido no caso das dívidas dos Estados com o Banco Central. Mas ele exacerba o comportamento assimétrico do IGP (que tende a crescer mais quando o real deprecia do que diminuir quando ele aprecia). Em suma, a indexação inadequada da dívida é a principal fragilidade do contrato, por fragilizar a lógica interna do PAF, como fica amplamente demonstrado quando o arcabouço que o sustenta é explicitado.

\footnotetext{
${ }^{5} \mathrm{O}$ deslocamento da trajetória da dívida propriamente dita foi particularmente intenso na esteira da depreciação nominal do câmbio, de forte impacto no indexador do valor do principal da dívida (o IGP), nos anos 2001-2003.
} 


\section{CONCLUSÃO}

Apesar de pouco entendido, o programa de renegociação da dívida dos Estados é de grande sofisticação, guardando importante coerência interna. As hipóteses básicas são coerentes com a convergência da dívida no período desejado, se considerados pontos de partida coerentes também com os tetos da Lei de Responsabilidade Fiscal que complementou a arquitetura deste pacto federativo. A implementação do PAF e a discussão do espaço de endividamento dos Estados têm a ganhar, portanto, com o uso deste modelo formal que aponta o endividamento máximo seguro para os entes subnacionais. A robustez deste edifício, no entanto, depende do realismo de suas hipóteses, e a indexação ao IGP-DI demonstrou não ser realista. Independente da discussão da compatibilidade de taxas de juros de longo prazo de $6 \%$ no atual estágio econômico do país, a questão da indexação pelo IGDP merece urgente atenção. Só assim o pacto federativo pode ser honrado e os estado investir na proporção das demandas da sociedade, sem prejuízo da União.

\section{REFERÊNCIAS}

BRASIL. Lei Complementar $\mathrm{n}^{\circ}$ 101, de 4 de maio de 2000. Disponível em: http://www.planalto.gov.br.

BRASIL. Lei 7.977, de 27 de dezembro de 1989. Disponível em: http://www.planalto.gov.br. BRASIL. Lei 8.727, de 5 de novembro de1993. Disponível em: http://www.planalto.gov.br.

BRASIL. Lei 9.496, de 11 de setembro de 1997. Disponível em: http://www.planalto.gov.br. 
